\section{P-256 \\ RETURN TO WORK AFTER BREAST CANCER: AN OPPORTUNITY OF TUNISIAN WOMEN EMPOWERMENT}

'Lamia Bouzgarrou, Amen Moussa, Slama Anis, Amira Omrane, Hayet Laajili. 'University of Monastir, Tunisia

\subsection{6/OEM-2021-EPI.253}

Introduction Returning to work after breast cancer, is associated with different benefits such financial independence and engaging in a meaningful occupation, but often limited by several difficulties.

Objectives To assess the return to work among active Tunisian women after breast cancer and to identify its determinants and barriers.

Methods Women treated for breast cancer, in one of the biggest Tunisian gynecology centers, at least two years and at most five years before the cross-sectional survey onset, and under a regular employment contract at diagnosis time, were included $(n=112)$. Socio-demographic and medical characteristics were collected from medical files. Return to work and its circumstances were investigated during a face-to-face interview.

Results At diagnosis, 26\% of patients were under 41 years old (mean age $=48 \pm 11$ years). Patients worked in the public sector in $87 \%$ of cases, in a middle or senior management position in $35 \%$ and in a limited-term employment contract by $4 \%$ of cases. After cancer, 97\% of women needed a sick leave (mean duration $=9.5 \pm 2.5$ months). Sick leave was significantly prolonged among patients working in the public sector $(\mathrm{p}=$ $0.01)$, blue collar officiers $(\mathrm{p}=0.01)$, unlimited employment contract $(p=0.02)$ and surgical treatment $(p=0.01)$. At investigation time, return to work was noted among $72 \%$ of patients, with regain of initial occupied workstation only in $5 \%$ of cases. After returning to work, $76 \%$ of patients reported incomes decrease and $49 \%$ of them co-workers discrimination. Hostility at work motivated $3 \%$ of patient to ask for early retirement. Return to work was significantly higher among married women $(\mathrm{p}=0.02)$, blue-collar officers category $(p=0.01)$, in case of early diagnosis cancer stage and better health auto assessment $(\mathrm{p}=0.01)$.

Conclusion Return to work, an important step in the recovery of a normal life, should be better prepared through a reinforced collaboration between occupational and attending physicians.

\section{P-257 WORK-FAMILY CONFLICT AS A RISK FACTOR OF BACK PAIN AMONG NURSES.}

${ }^{1}$ Hibat Allah Mosbah, Ines Rassas, Marouen Hayouni, Aouatef Mahfoudh, Amira Khelil, Adnene Hanchi, Mohamed Akrout, Irtyah Merchaoui. 'Fattouma Bourguiba Hospital, Tunisia

\subsection{6/OEM-2021-EPI.254}

Introduction Work Family Conflict (WFC) is one of the most specific sources of stress in the nursing profession. Although the impact of this phenomenon on both family life and mental health of nurses has been well documented, its role as a risk factor for musculoskeletal disorders (MSDs) has only recently been the subject of scientific research.

Aim To examine the impact of WFC on the occurrence of back pain among nursing staff in a public district hospital in Tunisia.
Methods This cross-sectional study was conducted on nurses assigned to a District Hospital in Tunisia, whose job seniority was at least one-year. Data collection was based on an administered questionnaire on the socio-demographic and occupational characteristics of the participants. Psychosocial factors at work and work-family interface were evaluated using the Organizational Psychological Constraints questionnaire and Carlson's work-family conflict scale. Screening of musculoskeletal disorders of the spine was conducted through a Nordicstyle questionnaire.

Results 72 nurses were included in this study with a mean age of $42.3 \pm 10.8$ years. Over the past 12 months, the prevalence of back pain has been $77.8 \%$. It was associated with gender $(p=0.009)$, age $(p=0.021)$, marital status $\left(p<10^{-3}\right)$, BMI $(p=0.009)$, history of chronic disease $(p=0.009)$, job seniority $(p=0.008)$, the duration of home-hospital journey $(p=0.024)$, work-family conflict $\left(\mathrm{p}<10^{-3}\right)$ and family-work conflict $(p=0.005)$. Multivariate analysis showed that the significant predictors of back pain were personal history of chronic diseases $(p=0.009 ;$ OR $=6.5 ;$ CI95\% $=[1.6-26.7])$ and WorkFamily Conflict $\left(\mathrm{p}<10^{-3} ;\right.$ OR $=11.8 ;$ CI95\% $=[2.9-$ 47.3]).

Conclusion Work-family conflict is one of the most important stress factors that cause back pain among nurses. The extent of this phenomenon in this professional category justifies its consideration in any precautionary approach to prevent musculoskeletal disorders in healthcare settings.

\section{P-259 WORK-RELATED BIOMECHANICAL EXPOSURE AMONG NURSES: SEMI-QUANTITATIVE ERGONOMIC RISK ASSESSMENT}

${ }^{1}$ Lamia Bouzgarrou, Ben Afia Latifa, Kamoun Salma, Dafaa Amine, Touka Yahyaoui, Irtyah Merchaoui, Neila Chaari. 'University of Monastir, Tunisia

\subsection{6/OEM-2021-EPI.255}

Introduction Care activities associated biomechanical constraints induce musculoskeletal disorders with heavy consequences, notably for exposed nurses.

Objectives This study aimed to assess biomechanical exposure among nurses in 28 patient hospitalization services.

Methods Concerned services were classified according to the nurses' usual physical workload in 'light', 'moderate', 'important' and 'high' physical demanding group. A specific software was used to encode nurse activity observations. Indeed, at regular intervals of 15 seconds, each relevant biomechanical parameter of work situation is observed and instantly associated to a physical load score. The 'patient handling score' integrates both the adopted posture and the patient caracteristics . In order to estimate the overall physical arduousness, the software calculates a global score and distributes it according to the Chamoux scale.

Results Most constraining postures were adopted during significantly longer periods in 'heavy' services. 'Standing with leaning or twisted back' was observed during 22.99\% of working time in 'high physical demanding service', during $19.23 \%$ in 'important physical demanding services', during $15.60 \%$ and $15.33 \%$ in 'moderate' and 'light' demanding ones. The fraction of time spent with 'Arms raised over the shoulders' decreased from $2.14 \%$ in heavy demanding services to 1.44 in moderate ones. In total, patient handling activity took $0.71 \%$ 
of working time. Moreover, 'High physical demanding service' were significantly concerned by largest fraction of handling time $(1.77 \%)$, by lower degree of autonomy of handled patients $(1.51 \%$ of total working time), and by handling patients having weight exceeding $65 \mathrm{~kg}(1.57 \%$ of total working time). According to the Chamoux scale, global physical activity was classified rather heavy in all services groups, with an average score significantly increasing from 7.25 to 7.76 from' light' to 'high' physical demanding services $($ Anova $=0.039)$.

Conclusion Our investigation objectified variable levels of biomechanical constraints in hospital services. Ergonomic and organizational preventing measures should be set up to prevent serious consequences among caregivers, in particular those affected to heavy services.

\section{P-260 FATAL WORK-RELATED INJURIES INVOLVING MOTORCYCLE BY SEX, AGE AND OCCUPATIONAL SECTORS IN BRAZIL, 2007 TO 2018}

${ }^{1}$ Cleber Cremonese, Homègnon Antonin Ferréol Bah, Mateus Lisboa, Aline Cristina Gusmão, Lenira Ferreira Ribeiro, Rafael Buralli, Flávia Ferreira-Sousa, Eugenia Maria Rodrigues, Vilma Sousa Santana. 'Federal University of Bahia, Brazil

\subsection{6/OEM-2021-EPI.256}

Introduction Brazilian records show a high rate of traffic accidents involving motorcycles (30\% of deaths, 55\% of hospitalizations). The number of Brazilian workers who use motorcycles is increasing and it is necessary to understand the context of these accidents in order to develop public policies and promote education.

Objectives To describe the proportion of mortality by workrelated injuries (PM_WRI) involving motorcycle in Brazil, 2007-2018.

Methods The study was conducted with data from the Brazilian Mortality Information System for those aged 18-65 years, in 2007-2018. Motorcycle-related deaths correspond codes V20 to V29 (ICD-10). PM_WRI are presented by calendar year, sex, age and occupational groups.

Results There were 121,124 records of fatal injuries involving motorcycles, with a increasing linear trend from 7,502 in 2007 to 9,725 in 2018. Work-related data (WRD) were registered for only 48,716 (40.2\%) cases, from which 3,692 were classified as occupational. From 2007 to 2010, the PM_WRI went from $7.6 \%$ to $8.9 \%$ (maximum) when it started to fall until 2015 (6.4\% minimum). The average for the last three years was $7.4 \%$. No significant difference of PM_WRI by sex was found. PM_WRI increased with age but declined in the oldest age group (50-65 age years). Occupation was registered for 33,784 cases (69\% of the WRD). The highest PM_WRI was estimated among workers from service industry $(1 \overline{4} .3 \%)$ followed by administrative services (13.6\%). Agriculture had the largest number of motorcycle-related deaths (35\%) but only $3.1 \%$ was recognized as work-related.

Conclusion The work-related data in death certificates were poorly recorded, limiting conclusions on the contribution of labor on motorcycle associated deaths. PM WRI estimates were presumably underestimated and findings could be biased. Motorcycle-related deaths doubled over the study time and the role of labor for this need to be better understood. Improvements in the quality and completion of WRD are urgently needed and prevention programs implemented.

\section{P-261 SEMI-QUANTITATIVE ERGONOMIC ASSESSMENT OF BIOMECHANICAL RISK FACTORS OF THE UPPER LIMBS' MUSCULOSKELETAL DISORDERS AMONG TUNISIAN JEWELRY CRAFTSMEN}

'Lamia Bouzgarrou, Ben Afia Latifa, Asma Kheder, Amira Omrane, Faten Hermassi, Taoufik Khalfallah. 'University of Monastir, Tunisia

\subsection{6/OEM-2021-EPI.257}

Introduction Jewelry handcrafting activity is strongly associated with biomechanical constraints and high risk of upper limb musculoskeletal disorders (UL-MSDs).

Objective This study aims to assess biomechanical constraints and specific tasks and subtasks at risk of UL-MSDs among jewelry craftsmen.

Methods Open observations were conducted in several jewelry workshops during whole working days. These observations allowed us to identify representative work periods, tasks and subtasks and to set the number of recordings at fourteen according to 'homogeneous exposure group' (HEG) sampling recommendations. For each video recording (duration $=30$ to 40 minutes), 100 images were extracted through regular stops on fixed time intervals. In each image, postures were encoded and analyzed by ERGOROM software. Gestural Variability Score (GSV) was calculated based on variability of posture from one image to the next.

Results Six main tasks composed handcrafting jewelry activity (mold making; fusion and gluing metal; demoulding; sanding; crimping and polishing). These tasks were associated to eleven subtasks (the creation of impression in the mold, the heating of the metal, the welding during assembly of the piece.). Objective analysis revealed that jewelers spent 38\%of their working time with the neck in flexion exceeding $40^{\circ}$ or extension, and the shoulders in adduction, extension or visible rotation during $60.8 \%$ of the time. The elbow articulation was maintained in extreme pronation in $40.4 \%$ of the working time and flexion between $60^{\circ}$ and $100^{\circ}$ during $78.1 \%$ this time. The ulnar deviation of the wrist was observed during $40.9 \%$ of work time and the pinch grip for over $79.5 \%$ of it. In addition, the high variability score was noted especially for elbow joint and shoulder, reflecting a rapid postural change and high repetitiveness.

Conclusion Our results, suggest the necessity of preventive actions among jewelers craftsmen, with mainly the introduction of ergonomic design of hand tools .

\section{P-268 METAL EXPOSURE AND RISK OF PARKINSON'S DISEASE: SYSTEMATIC REVIEW AND META-ANALYSES}

${ }^{1}$ Yujia Zhao, Susan Peters, Roel Vermeulen, Anushree Ray. 'Utrecht University, Netherlands

\subsection{6/OEM-2021-EPI.258}

Introduction Parkinson's disease (PD) is the second most common neurodegenerative disorder. Metal exposure has been suggested as a possible environmental risk factor by many epidemiological studies, but results have been inconsistent. Additionally, existing reviews on metal exposure and PD risk lack careful screening for study design and quality, especially on the exposure assessment.

Objectives We aimed to synthesize the literature on metal exposure and PD risk by examining the quality of the overall study and exposure assessment method. 